\title{
Inspiratory Muscle Training in Obstructive Sleep Apnea Associating Diabetic Peripheral Neuropathy: A Randomized Control Study
}

\author{
Samah A. Moawd $\mathbb{D},{ }^{1,2}$ Alshimaa R. Azab $\mathbb{D}^{2,3}$ Saud M. Alrawaili $\mathbb{D}$, ${ }^{2}$ \\ and Walid Kamal Abdelbasset $\mathbb{B}^{2,4}$ \\ ${ }^{1}$ Department of Physical Therapy for Cardiovascular/Respiratory Disorders and Geriatrics, Faculty of Physical Therapy, \\ Cairo University, Giza, Egypt \\ ${ }^{2}$ Department of Health and Rehabilitation Sciences, College of Applied Medical Sciences, Prince Sattam bin Abdulaziz University, \\ Alkharj, Saudi Arabia \\ ${ }^{3}$ Department of Physical Therapy for Pediatrics, Faculty of Physical Therapy, Cairo University, Giza, Egypt \\ ${ }^{4}$ Department of Physical Therapy, Kasr Al-Aini Hospital, Cairo University, Giza, Egypt
}

Correspondence should be addressed to Walid Kamal Abdelbasset; walidkamal.wr@gmail.com

Received 13 March 2020; Revised 15 May 2020; Accepted 1 June 2020; Published 12 June 2020

Academic Editor: Vida Demarin

Copyright (c) 2020 Samah A. Moawd et al. This is an open access article distributed under the Creative Commons Attribution License, which permits unrestricted use, distribution, and reproduction in any medium, provided the original work is properly cited.

\begin{abstract}
Objective. This work is aimed at assessing the effects of inspiratory muscle training on lung functions, inspiratory muscle strength, and aerobic capacity in diabetic peripheral neuropathy (DPN) patients with obstructive sleep apnea (OSA). Methods. A randomized control study was performed on 55 patients diagnosed with DPN and OSA. They were assigned to the training group (IMT, $n=28$ ) and placebo training group (P-IMT, $n=27$ ). Inspiratory muscle strength, lung functions, and aerobic capacity were evaluated before and after 12 weeks postintervention. An electronic inspiratory muscle trainer was conducted, 30 min a session, three times a week for 12 consecutive weeks. Results. From seventy-four patients, 55 have completed the study program. A significant improvement was observed in inspiratory muscle strength $(p<0.05)$ in the IMT group while no changes were observed in the P-IMT group $(p>0.05)$. No changes were observed in the lung function in the two groups $(p>0.05)$. Also, $\mathrm{VO}_{2} \mathrm{max}$ and $\mathrm{VCO}_{2}$ max changed significantly after training in the IMT group $(p<0.05)$ while no changes were observed in the P-IMT group $(p>0.05)$. Other cardiopulmonary exercise tests did not show any significant change in both groups $(p>0.05)$. Conclusions. Based on the outcomes of the study, it was found that inspiratory muscle training improves inspiratory muscle strength and aerobic capacity without a notable effect on lung functions for diabetic patients suffering from DPN and OSA.
\end{abstract}

\section{Introduction}

Diabetes mellitus (DM) is a global disease in which blood glucose level regulation is affected causing major health implications. The global epidemic recording of diabetes was about 400 million people in 2013 and expected to reach 600 million by $2035[1,2]$. Type 2 diabetes (T2D) ranged more than $90 \%$ of all diabetic patients and it affects multiple body systems leading to cardiovascular, cerebrovascular, and renal complications particularly in poorly controlled diabetes and may cause death $[3,4]$. Diabetic patients have a double risk for mortality than nondiabetics $[5,6]$.

More than $60 \%$ of diabetic patients are commonly suffering from nervous system damage, known as diabetic peripheral neuropathy (DPN) and defined as impairments in metabolic and microvessel functions due to chronic hyperglycemia and cardiovascular dysfunctions. These impairments are symmetrical and longstanding [7]. DPN affects approximately $30 \%$ of diabetic patients aged more than $40[8]$. 
Obstructive sleep apnea (OSA) is known as partial or complete episodes of upper airway obstruction during sleep. Commonly, episodic airway obstruction is associated with oxyhemoglobin desaturations and sleep arousals. OSA symptoms include chronic snoring, insomnia, gasping and breathholding, unrefreshing sleep, and daytime sleepiness [9].

OSA is a frequent disorder characterized by apnea and hypopnea even with continued respiratory efforts and occurs for ten or more seconds because of a collapsed upper airway $[10,11]$. This is habitually associated with sleep disturbances, arousals, and oxygen saturation impairments [12]. Episodes of upper airway obstruction during sleep, repetitive short interruptions of sleep, and impairment of oxyhemoglobin saturation are related to OSA $[13,14]$. Symptoms of fatigue, excessive daytime sleepiness, and morning headaches occur due to activating the sympathoadrenal system, oxidative stress, systemic inflammation, and impaired adipokines. Subsequently, these symptoms result in an increased cardiovascular disease sustainability, higher blood pressure, and metabolic syndrome in diabetic patients $[15,16]$.

Lately, it has been reported that OSA and DPN are strongly correlated and OSA is prevalent in $23-87 \%$ of T2D [17] indicating that OSA and T2D are a risk factor for each other [6]. Besides, OSA negatively affects the treatment of T2D and may worsen preexisting OSA. The causes of the relationship between the OSA and PDN remain unknown [18]. It is a bidirectional association between OSA and T2D as OSA may aggravate and amplify T2D and subsequent complications such as DPN. Eventually, OSA may have contributed to $\mathrm{T} 2 \mathrm{D}$, resulting in a vicious circle. In addition, mechanisms including oxidative stress, inflammation, AGEs, and PKC signaling contributed to DPN and OSA. These underlying mechanisms may occur simultaneously in patients with T2D leading to DPN and OSA [19-21].

Only few studies have assessed the influences of inspiratory muscle training (IMT) in DPN with OSA [22], while many documents have reported the efficacy of this type of exercise on several medical issues [23, 24]. The effects of IMT on aerobic capacity and inspiratory muscle strength are debatable. Conducting the IMT resulted in improvements in inspiratory muscle strength and aerobic capacity in asthmatics [25], while another study found that IMT did not show any changes in aerobic capacity and lung functions in T2D [26]. Therefore, we aimed to assess the effects of IMT on lung functions, inspiratory muscle strength, and aerobic capacity in PDN with OSA on hypothesizing that IMT could be an effective modality for enhancing lung functions, inspiratory muscle strength, and aerobic capacity in PDN with OSA.

\section{Methods}

2.1. Subjects. A randomized controlled trial was conducted on 55 diabetic patients, their criteria according to the National Diabetes Data Group criteria [27], recruited from the Outpatient Clinic of Endocrinology department in the university hospital, Prince Sattam bin Abdulaziz University. Moderate DPN patients were selected in this study in keeping with the neuropathy symptom score (NSS) and neuropathy disability score (NDS) [28]. Also, patients were included in the study if their maximal inspiratory pressure (PImax) is less than or equal $70 \%$ predicted [29]. In addition, they were diagnosed with mild to moderate OSA (AHI 5 to 30/h with clinical symptoms). Polysomnogram (PSG) was used for OSA diagnosis; sleep was assessed by one-night polysomnogram (PSG) that was performed by a Somon Medics Gmbh (Am SonnenstuhL63, D-97236 Rander acker, Germany, Type: SOMNO Screen ${ }^{\mathrm{TM}}$ Plus, SN: 4259, kw45: 2014). Thermal airflow sensors (thermistor) were used for respiratory sensors, nasal, and oral signals. Apneas and hypopneas are scored and added to determine the AHI [30]. Regarding the American Academy of Sleep Medicine definitions, an apnea was defined as $\geq 90 \%$ drop in the thermistor excursion signal of $\geq 10 \mathrm{sec}$ and hypopnea which was defined as a decrease in thermistor signal by $>30 \%$ for $>10 \mathrm{sec}$ accompanied by a decrease of oxyhemoglobin saturation $\geq 4 \%$. The patient was considered to have sleep apnea syndrome (SAS) if the apnea hypopnea index (AHI) is $\geq 15$ or if $\mathrm{AHI} \geq 5$ is associated with insomnia, cardiovascular comorbidities or diurnal symptoms mainly EDS, impaired cognition, or mood changes [31].

Patients with respiratory or cardiac problems; end-stage renal disease (ESRD); severe chronic liver disease; chronic pain; and advanced metabolic, neuropsychiatric, or endocrinal disorders affecting sleep; and $\mathrm{BMI}>34 \mathrm{~kg} / \mathrm{m}^{2}$ were excluded from the study. Also previous patients with a diagnosis of type 1 diabetes or the presence of an acute illness at study enrollment, history of medication intake affecting sleep, and who are heavy smokers or drug abusers were excluded. In addition, patients underwent regular aerobic exercise were not included in this study as it improves inspiratory muscle strength so only sedentary patients were recruited $[32,33]$.

This study was ethically approved by the local research ethical committee of the physical therapy department at Prince Sattam bin Abdulaziz University in reference to the standards of the Helsinki Declaration and CONSORT guidelines (No: RHPT/019/032). All patients were informed that their participation is voluntary and instructed to sign the consent form before beginning the study procedure.

2.2. Assessments. Medical history, body weight, and height were recorded for each participant. Body mass index (BMI) was calculated by dividing weight in kilograms on height square in meters. Subjects were instructed to come fasting for taking of the samples, and assessment of blood glucose and $\mathrm{HbAlc}$ were done. Medical history, physical examination, and the determination of PImax were done. Included patients were randomly assigned into the IMT and placebo IMT (P-IMT) groups. Lung functions, inspiratory muscle strength, and aerobic capacity were assessed before and after 12 weeks of the study period.

2.3. Inspiratory Muscle Strength. The values of maximal inspiratory pressures have been obtained using the POWERbreathe $\mathrm{KH} 2$ equipment, and the maximal inspiratory pressure (PImax) has been recorded in $\mathrm{cmH}_{2} \mathrm{O}$. For PImax measurement, subjects generated a maximal inspiration from 


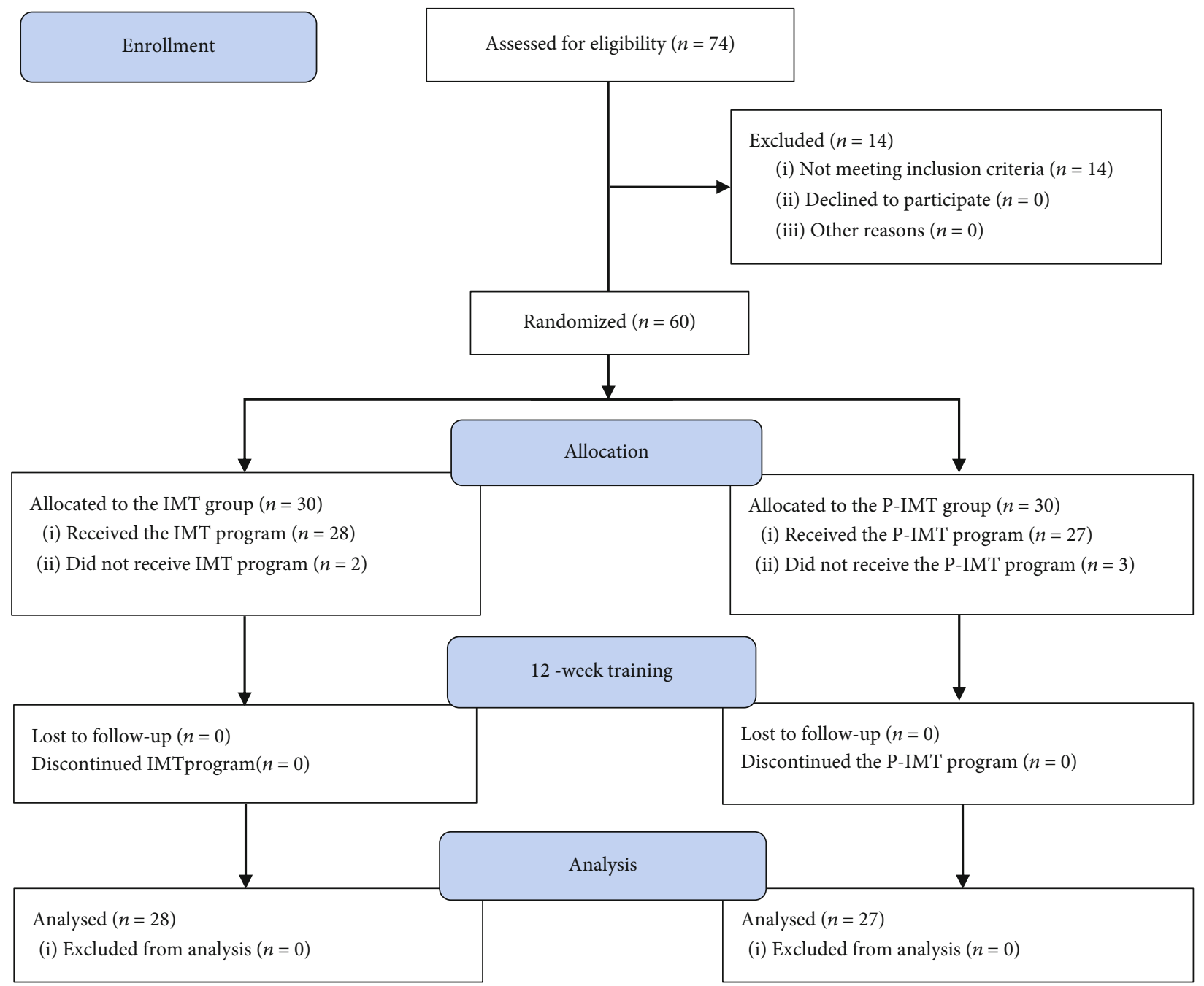

FIgURE 1: The flowchart of the study.

a residual lung volume and against a constant resistance. The maneuvers were carried out and the participants were instructed to sit with knees flexed to $90^{\circ}$ and close the nose using the thumb and index fingers. A warm-up exercise was in the form of a complete approximately five breaths against resistance. Three measurements were obtained making sure that a maximum value was reached $[34,35]$.

2.4. Lung Functions. The Minispir ${ }^{\circledR}$ Light spirometer with Winspiro ${ }^{\circledR}$ Light software was utilized to measure lung function. Patients were seated with flexed knees at $90^{\circ}$ and held three deep breaths, inspired up to the total lung capacity (TLC), and then exhaled all the air to their residual volume (RV) to obtain the variables FEV1 (forced expiratory volume in $1 \mathrm{~s}$ ), FVC (forced vital capacity), and maximal voluntary ventilation (MVV) and FEV1/FVC. The test was repeated at least three times until the system considered the best maneuver as more reproducible and acceptable, considering the reference values for the adult Brazilian population [36].

2.5. Aerobic Capacity. Cardiopulmonary exercise test (CPET) was conducted using a treadmill (Centurium 300, Micromed,
Brazil). The software ErgoPCElite ${ }^{\circledR}$ was associated with 12lead electrocardiogram (Micromed, Brazil). Temperature $\left(18-22^{\circ} \mathrm{C}\right)$ and humidity (50-70\%) were the optimal condition for gathering the parameters; a gas analyzer is attached with a facemask during exercise. There was no verbal communication from the patients during the test, telling the patients to use hand signals to express fatigue level. The termination of the test was done by the monitor, or by the patients reporting about exhaustion [37].

2.6. Intervention. Both groups were recommended to maintain their regular activity daily livings and adhere to pulmonologist instructions. The program was supervised by professional physiotherapists in the physical therapy outpatient clinic.

An electronic inspiratory muscle trainer (TRAINAIR ${ }^{\circledR}$, Project Electronics Ltd., UK) was connected to the computer and used for inspiratory muscle training. It consists of a computer biofeedback system with software and electronic pressure manometer. The pressure produced by it is about 0 $-300 \mathrm{cmH}_{2} \mathrm{O}$. The training of the patients was referred to as their capacity with a fixed load of $75 \%$ of PImax. Each 
TABle 1: Baseline demographic and clinical characteristics of the study groups.

\begin{tabular}{|c|c|c|c|}
\hline Variables & $\begin{array}{l}\text { IMT group } \\
\quad(n=28)\end{array}$ & $\begin{array}{l}\text { P-IMT group } \\
\quad(n=27)\end{array}$ & $p$ value \\
\hline Age & $55.5 \pm 9.8$ & $59.5 \pm 4.8$ & 0.061 \\
\hline Gender $(\mathrm{M} / \mathrm{F})$ & $20 / 8$ & $22 / 5$ & 0.381 \\
\hline BMI $\left(\mathrm{kg} / \mathrm{m}^{2}\right)$ & $29.2 \pm 3.9$ & $27.9 \pm 4.8$ & 0.274 \\
\hline HbAlc (\%) & $7.3 \pm 1.6$ & $7.2 \pm 1.9$ & 0.833 \\
\hline AHI (events) & $32 \pm 11.7$ & $31 \pm 10.8$ & 0.743 \\
\hline \multicolumn{4}{|c|}{ Lung functions (\% predicted) } \\
\hline FEV1 & $105 \pm 29$ & $96 \pm 13$ & 0.146 \\
\hline FVC & $103 \pm 29$ & $92 \pm 10$ & 0.067 \\
\hline MVV & $80 \pm 18$ & $79 \pm 17$ & 0.833 \\
\hline \multicolumn{4}{|c|}{ Inspiratory muscle functions } \\
\hline $\operatorname{PImax}\left(\mathrm{cm} \mathrm{H}_{2} \mathrm{O}\right)$ & $56 \pm 13$ & $52 \pm 10$ & 0.207 \\
\hline PImax (\% predicted) & $58 \pm 11$ & $57 \pm 10$ & 0.726 \\
\hline \multicolumn{4}{|c|}{ Cardiopulmonary exercise test } \\
\hline $\mathrm{VO}_{2} \max (\mathrm{ml} / \mathrm{kg} / \mathrm{min})$ & $17.6 \pm 3.4$ & $19.4 \pm 3.5$ & 0.058 \\
\hline $\mathrm{VCO}_{2} \max (\mathrm{ml} / \mathrm{kg} / \mathrm{min})$ & $29.6 \pm 3.9$ & $28.0 \pm 7.1$ & 0.303 \\
\hline HR rest (bpm) & $76.9 \pm 6.0$ & $75.3 \pm 6.7$ & 0.354 \\
\hline HR max (bpm) & $140.4 \pm 11.0$ & $141.5 \pm 9.4$ & 0.692 \\
\hline $\mathrm{SBP}$ rest $(\mathrm{mmHg})$ & $110.5 \pm 10.4$ & $111.3 \pm 6.9$ & 0.739 \\
\hline SBP $\max (\mathrm{mmHg})$ & $171.3 \pm 15.6$ & $178.8 \pm 17.3$ & 0.097 \\
\hline $\mathrm{DBP}$ rest $(\mathrm{mmHg})$ & $69.7 \pm 6.5$ & $68.1 \pm 4.2$ & 0.285 \\
\hline DBP $\max (\mathrm{mmHg})$ & $87.5 \pm 7.1$ & $90.0 \pm 9.3$ & 0.266 \\
\hline
\end{tabular}

IMT: inspiratory muscle training; P-IMT: placebo-inspiratory muscle training; BMI: body mass index; HbAlc: glycosylated hemoglobin; AHI: apnoea-hypopnoea index.

training was consisted of six cycles of thirty breaths. Each cycle consisted of around $4 \mathrm{~min}$ of resisted breathing. The resting period was $1 \mathrm{~min}$ after the first cycle, $45 \mathrm{sec}$ after the second and third cycles, and $40 \mathrm{sec}$ in fourth and fifth cycles up to the sixth cycle. The total duration of the session was approximately $30 \mathrm{~min}$, three times a week for 12 consecutive weeks. Breaths through the device were applied by wearing a nose clip [38]. The P-IMT group was trained at a low training intensity ( $\leq 10 \%$ of PImax) with the same exercise protocol.

2.7. Statistical Analysis. Data were statistically analyzed utilizing SPSS version 20 (IBM Corp, Armonk, NY, USA). The Shapiro-Wilk test was used to assess the normality of data distribution. Characteristics of the sample and treatment effect between groups were explored using the unpaired $t$ -test, while the paired $t$-test was used to compare post mean values within each group. Analyzed data are shown as mean \pm standard deviation. Statistical significance was set at $p<0.05$.

\section{Results}

Figure 1 shows the flowchart of the current study. Of the 74 patients with PDN, 14 did not meet the inclusion criteria.
60 patients were randomized into the IMT (30) and P-IMT (30) groups; two patients from the IMT group and three patients from the P-IMT group later dropped out without defined reasons. Therefore, 28 patients from the IMT group and 27 patients from the P-IMT group completed the study and their results were analyzed postintervention.

As presented in Table 1, there were no significant differences between the groups regarding baseline demographic and clinical characteristics of the study (age, gender, BMI, $\mathrm{HbA1c}$, AHI, lung functions, inspiratory muscle functions anthropometric, and cardiopulmonary exercise tests; $p>$ 0.05 ) before training. Analyzing the after-training mean values, no significant changes were observed regarding lung functions in the IMT and P-IMT groups $(p>0.05)$, while it was detected that the IMT group shows greater improvement in FVC and FEV1 than the P-IMT group $(p<0.05)$. PImax improved in the IMT group $(p<0.05)$, while no significant changes were observed in the P-IMT group $(p>0.05)$. $\mathrm{VO}_{2} \max$ and $\mathrm{VCO}_{2}$ max improved postintervention as compared with before training $(p<0.05)$ in the IMT group and did not change in the P-IMT group $(p>0.05)$. Other cardiopulmonary exercise testing variables showed no changes after training in the two groups $(p>0.05)$. Comparing between the IMT and P-IMT groups after training, there were significant differences between the two groups in FVC, FEV1, PImax, $\mathrm{VO}_{2} \max , \mathrm{SBP} \max$, and DBP $\max (p<0.05)$ in favor of the IMT group as detailed in Table 2.

\section{Discussion}

The current study was proposed to evaluate the effect of IMT on lung function and aerobic capacity in PDN with OSA. It is hypothesized that IMT is an effective method for improving lung function and aerobic capacity. The finding of this study showed improvements in inspiratory muscle strength and aerobic capacity without changes in the lung function in PDN with OSA. Also, we observed that PImax and PImax\% were lower than the predicted values before intervention. This observation was supported by Kilicli et al. who approved that T2D is associated with lower values of PImax and PImax\% [39]. Regarding lung functions, it has been reported that there were no changes in FEV1, FVC, and MVV because of normal lung functions at the beginning of the study.

Commonly, PDN and OSA lead to a deprived glycemic control and OSA is associated with a lack of aerobic capacity due to alterations of the sympathetic nervous system activity, hypothalamic-pituitary-adrenal axis, and formation of reactive oxygen species that lead to an increase of inflammatory cytokines, tumor necrosis factor, and adipocyte-derived factors [40,41]. A prior study has approved that patients with T2D and OSA have impaired inspiratory muscle strength when compared with the matched reference value of non-OSA individuals [42]. In addition, it was demonstrated that the muscle strength of the upper airways is strongly correlated with inspiratory pumping muscle strength in OSA patients [43]. Also, hypoxemia and hypercarbia of the chemoreflex may increase the activity of the sympathetic nervous system that results in OSA-related comorbidities [44, 45]. 
TABle 2: The differences in the mean values of all outcome measures before and after training in the two groups.

\begin{tabular}{|c|c|c|c|c|c|c|}
\hline \multirow{2}{*}{ Variables } & \multicolumn{3}{|c|}{ IMT $(n=28)$} & \multicolumn{3}{|c|}{ P-IMT $(n=27)$} \\
\hline & Pre & Post & $p$ value & Pre & Post & $p$ value \\
\hline \multicolumn{7}{|c|}{ Lung functions (\% predicted) } \\
\hline FEV1 & $105 \pm 29$ & $107 \pm 18$ & 0.757 & $96 \pm 13$ & $91 \pm 17^{*}$ & 0.231 \\
\hline FVC & $103 \pm 29$ & $106 \pm 18$ & 0.643 & $92 \pm 10$ & $88 \pm 13^{*}$ & 0.211 \\
\hline MVV & $80 \pm 18$ & $82 \pm 13$ & 0.635 & $79 \pm 17$ & $76 \pm 14$ & 0.482 \\
\hline \multicolumn{7}{|c|}{ Inspiratory muscle functions } \\
\hline PImax $\left(\mathrm{cmH}_{2} \mathrm{O}\right)$ & $56 \pm 13$ & $121 \pm 22$ & $<0.001$ & $52 \pm 10$ & $57 \pm 11^{*}$ & 0.086 \\
\hline PImax (\% predicted) & $58 \pm 11$ & $125 \pm 17$ & $<0.001$ & $57 \pm 10$ & $61 \pm 9^{*}$ & 0.128 \\
\hline \multicolumn{7}{|c|}{ Cardiopulmonary exercise test } \\
\hline $\mathrm{VO}_{2} \max (\mathrm{ml} / \mathrm{kg} / \mathrm{min})$ & $17.6 \pm 3.4$ & $24.7 \pm 6.4$ & $<0.001$ & $19.4 \pm 3.5$ & $20.1 \pm 2.4^{*}$ & 0.395 \\
\hline $\mathrm{VCO}_{2} \max (\mathrm{ml} / \mathrm{kg} / \mathrm{min})$ & $29.6 \pm 3.9$ & $29.1 \pm 3.3$ & 0.607 & $28.0 \pm 7.1$ & $27.0 \pm 6.1$ & 0.581 \\
\hline HR rest (bpm) & $76.9 \pm 6.0$ & $75.3 \pm 5.5$ & 0.303 & $75.3 \pm 6.7$ & $74.3 \pm 7.2$ & 0.599 \\
\hline HR max (bpm) & $140.4 \pm 11.0$ & $143.6 \pm 10.6$ & 0.273 & $141.5 \pm 9.4$ & $143.8 \pm 9.9$ & 0.385 \\
\hline SBP rest (mmHg) & $110.5 \pm 10.4$ & $108.3 \pm 12.9$ & 0.485 & $111.3 \pm 6.9$ & $110.5 \pm 7.6$ & 0.687 \\
\hline SBP max (mmHg) & $171.3 \pm 15.6$ & $167.0 \pm 12.7$ & 0.263 & $178.8 \pm 17.3$ & $182.5 \pm 15.8^{*}$ & 0.416 \\
\hline DBP rest (mmHg) & $69.7 \pm 6.5$ & $67.8 \pm 5.8$ & 0.253 & $68.1 \pm 4.2$ & $66.4 \pm 6.9$ & 0.279 \\
\hline DBP $\max (\mathrm{mmHg})$ & $87.5 \pm 7.1$ & $85.0 \pm 5.3$ & 0.141 & $90.0 \pm 9.3$ & $92.5 \pm 8.9^{*}$ & 0.317 \\
\hline
\end{tabular}

${ }^{*}$ Significant difference between groups postintervention $(p<0.05)$. IMT: inspiratory muscle training; P-IMT: placebo-inspiratory muscle training; FEV1: forced expiratory volume in $1 \mathrm{sec}$; FVC: forced vital capacity; MVV: maximal voluntary ventilation; PImax: maximum inspiratory pressure; $\mathrm{VO}_{2}$ max: maximal oxygen consumption; $\mathrm{VCO}_{2}$ max: maximal carbon dioxide exhaled; HRmax: maximal heart rate; SBP: systolic blood pressure; DBP: diastolic blood pressure.

In agreement with our findings, Correa et al. provided that IMT improves inspiratory muscle strength, aerobic capacity, and PImax values in T2D patients [26]. Also, it was reported that 4 weeks of IMT improves inspiratory muscle strength in OSA patients [46-48]. Furthermore, previous studies approved the positive effects of IMT on inspiratory muscle strength, functional status, diaphragmatic muscle performance, and circulation of the rest extremities [49, 50]. Moreover, similar to the current study results, it was documented that IMT improved PImax in healthy individuals through controlling the power breath during the endurance test of inspiratory muscles [51]. In addition, another study concluded that inspiratory and expiratory muscle training improves ventilator efficiency, inspiratory muscle strength, and aerobic capacity in normal individuals [52].

On the contrary, one study approved that a combination of aerobic exercise and IMT showed no efficient changes in aerobic capacity whether maximal oxygen uptake or other measures of the cardiopulmonary exercise test [53] that could result from the limited focus on respiratory muscles in comparison with aerobic exercise and/or the seminormal functional status of the included patients. Also, another study concluded that IMT improves inspiratory muscle strength but does not improve aerobic capacity in healthy older adults [54] which could be associated with the different baseline data.

It is believed that metaboreflex activation in inspiratory muscle leads to high blood flow to both the skeletal and inspiratory muscles in normal subjects [55] and chronic obstructive pulmonary disease patients [22]. On the other hand, diabetic patients had showed no improvement in aerobic capacity following IMT because of the muscle metaboreflex attenuation [56].

In spite of the strong relation between OSA and PDN, however, this relation is still not understood. Both of PDN and OSA lead to the inability to control the blood glucose level. Also, OSA is related to disturbed aerobic capacity while no studies confirmed these observations. Regarding the study results, inspiratory muscle strength and aerobic capacity had improved following IMT in patients suffering from PDN and OSA.

Some limitations were observed in the study. The main limitation is the short study period. Another limitation is that there were no intermediate and postintervention follow-up assessments. One more limitation is that the quality of life was not assessed postintervention. Future studies are needed to assess the effectiveness of IMT in diabetic patients with abnormal lung functions.

\section{Conclusions}

This randomized trial provided that IMT may improve inspiratory muscle strength and aerobic capacity in PDN with OSA. It also provides clinical implications of IMT in the treatment of PDN patients with OSA. IMT should be recommended in pulmonary rehabilitation programs, especially PDN patients with OSA.

\section{Data Availability}

Regarding manuscript 5036585, this study is a randomized control study and the data involved is available from the 
corresponding author upon request and privacy-related parts of the patient will not be provided.

\section{Conflicts of Interest}

The authors declare that they have no conflicts of interest.

\section{Acknowledgments}

This publication was supported by the Deanship of Scientific Research at Prince Sattam bin Abdulaziz University. The authors would like to acknowledge all patients who participated in the study.

\section{References}

[1] E. Selvin, C. M. Parrinello, D. B. Sacks, and J. Coresh, "Trends in prevalence and control of diabetes in the United States, 1988-1994 and 1999-2010," Annals of Internal Medicine, vol. 160, no. 8, pp. 517-525, 2014.

[2] A. A. Tahrani and A. Ali, "Obstructive sleep apnoea and type 2 diabetes," European Endocrinology, vol. 10, no. 1, pp. 43-50, 2014.

[3] S. Tesfaye, D. Selvarajah, R. Gandhi et al., "Diabetic peripheral neuropathy may not be as its name suggests," Pain, vol. 157, Supplement, pp. S72-S80, 2016.

[4] S. Nannapaneni, K. Ramar, and S. Surani, "Effect of obstructive sleep apnea on type 2 diabetes mellitus: a comprehensive literature review," World Journal of Diabetes, vol. 4, no. 6, pp. 238244, 2013.

[5] K. Mahmood, N. Akhter, K. Eldeirawi et al., "Prevalence of type 2 diabetes in patients with obstructive sleep apnea in a multi-ethnic sample," Journal of Clinical Sleep Medicine, vol. 5, no. 3, pp. 215-221, 2009.

[6] K. J. Reichmuth, D. Austin, J. B. Skatrud, and T. Young, “Association of sleep apnea and type II diabetes: a population-based study," American Journal of Respiratory and Critical Care Medicine, vol. 172, no. 12, pp. 1590-1595, 2005.

[7] E. L. Feldman, K. A. Nave, T. S. Jensen, and D. L. H. Bennett, "New horizons in diabetic neuropathy: mechanisms, bioenergetics, and pain," Neuron, vol. 93, no. 6, pp. 1296-1313, 2017.

[8] A. M. Stino and A. G. Smith, "Peripheral neuropathy in prediabetes and the metabolic syndrome," Journal of Diabetes Investigation, vol. 8, no. 5, pp. 646-655, 2017.

[9] American Academy of Sleep Medicine, "ICSD-2 International Classification of Sleep Disorders," in Diagnostic and Coding Manual, American Academy of Sleep Medicine, Westchester, IL, USA, 2nd edition, 2005.

[10] R. Heinzer, S. Vat, P. Marques-Vidal et al., "Prevalence of sleep-disordered breathing in the general population: the Hypnolaus study," The Lancet Respiratory Medicine, vol. 3, no. 4, pp. 310-318, 2015.

[11] V. A. Umoh, E. E. Akpan, U. E. Ekrikpo, A. U. Idung, and E. E. Ekpe, "The risk of obstructive sleep apnea among patients with type 2 diabetes mellitus," Nigerian Medical Journal, vol. 61, no. 1, pp. 32-36, 2020.

[12] M. P. Hermans, S. A. Ahn, Y. P. Mahadeb, and M. F. Rousseau, "Sleep apnoea syndrome and 10-year cardiovascular risk in females with type 2 diabetes: relationship with insulin secretion and insulin resistance," Diabetes/Metabolism Research and Reviews, vol. 29, no. 3, pp. 227-234, 2013.
[13] R. S. Aronsohn, H. Whitmore, E. van Cauter, and E. Tasali, "Impact of untreated obstructive sleep apnea on glucose control in type 2 diabetes," American Journal of Respiratory and Critical Care Medicine, vol. 181, no. 5, pp. 507-513, 2010.

[14] C. Girault, G. Brunin, F. Zerimech et al., "French Intensive Care Society, international congress - réanimation 2016," Annals of Intensive Care, vol. 6, no. S1, Supplement 1, p. 50, 2016.

[15] P. Zhang, R. Zhang, F. Zhao et al., "The prevalence and characteristics of obstructive sleep apnea in hospitalized patients with type 2 diabetes in China," Journal of Sleep Research, vol. 25, no. 1, pp. 39-46, 2016.

[16] Y. Mok, C. W. Tan, H. S. Wong, C. H. How, K. L. Tan, and P. P. Hsu, "Obstructive sleep apnoea and type 2 diabetes mellitus: are they connected?," Singapore Medical Journal, vol. 58, no. 4, pp. 179-183, 2017.

[17] C. V. Senaratna, J. L. Perret, C. J. Lodge et al., "Prevalence of obstructive sleep apnea in the general population: a systematic review," Sleep Medicine Reviews, vol. 34, pp. 70-81, 2017.

[18] P. Rajan and H. Greenberg, "Obstructive sleep apnea as a risk factor for type 2 diabetes mellitus," Nature and Science of Sleep, vol. 7, pp. 113-125, 2015.

[19] H. Storgaard, B. Mortensen, T. Almdal, M. Laub, and L. Tarnow, "At least one in three people with type 2 diabetes mellitus referred to a diabetes centre has symptomatic obstructive sleep apnoea," Diabetic Medicine, vol. 31, no. 11, pp. 14601467, 2014.

[20] K. Rasche, T. Keller, B. Tautz et al., "Obstructive sleep apnea and type 2 diabetes," European Journal of Medical Research, vol. 15, no. S2, 2010Supplement 2, 2010.

[21] H. Shen, J. Zhao, Y. Liu, and G. Sun, "Interactions between and shared molecular mechanisms of diabetic peripheral neuropathy and obstructive sleep apnea in type 2 diabetes patients," Journal Diabetes Research, vol. 2018, article 3458615, 15 pages, 2018.

[22] J. R. Vranish and E. F. Bailey, "Inspiratory muscle training improves sleep and mitigates cardiovascular dysfunction in obstructive sleep apnea," Sleep, vol. 39, no. 6, pp. 1179-1185, 2016.

[23] M. B. Bavarsad, A. Shariati, E. Eidani, and M. Latifi, "The effect of home-based inspiratory muscle training on exercise capacity, exertional dyspnea and pulmonary function in COPD patients," Iranian Journal of Nursing and Midwifery Research, vol. 20, no. 5, pp. 613-618, 2015.

[24] B. HajGhanbari, C. Yamabayashi, T. R. Buna et al., "Effects of respiratory muscle training on performance in athletes: a systematic review with meta-analyses," Journal of Strength and Conditioning Research, vol. 27, no. 6, pp. 1643-1663, 2013.

[25] L. A. Turner, T. D. Mickleborough, A. K. Mcconnell, J. M. Stager, S. Tecklenburg-Lund, and M. R. Lindley, "Effect of inspiratory muscle training on exercise tolerance in asthmatic individuals," Medicine and Science in Sports and Exercise, vol. 43, no. 11, pp. 2031-2038, 2011.

[26] A. P. S. Corrêa, J. P. Ribeiro, F. M. Balzan, L. Mundstock, E. L. Ferlin, and R. S. Moraes, "Inspiratory muscle training in type 2 diabetes with inspiratory muscle weakness," Medicine and Science in Sports and Exercise, vol. 43, no. 7, pp. 1135-1141, 2011.

[27] T. Huang, B. M. Lin, M. J. Stampfer, S. S. Tworoger, F. B. Hu, and S. Redline, "A population-based study of the bidirectional association between obstructive sleep apnea and type 2 
diabetes in three prospective U.S. cohorts," Diabetes Care, vol. 41, no. 10, pp. 2111-2119, 2018.

[28] World Health Organization (WHO), Definition and Diagnosis of Diabetes Mellitus and Intermediate Hyperglycemia: Report of a WHO/IDF Consultation, WHO, Geneva, 2006.

[29] T. Kisozi, E. Mutebi, M. Kisekka et al., "Prevalence, severity and factors associated with peripheral neuropathy among newly diagnosed diabetic patients attending Mulago hospital: a cross-sectional study," African Health Sciences, vol. 17, no. 2, pp. 463-473, 2017.

[30] J. A. Neder, S. Andreoni, M. C. Lerario, and L. E. Nery, "Reference values for lung function tests. II. Maximal respiratory pressures and voluntary ventilation," Brazilian Journal of Medical and Biological Research, vol. 32, no. 6, pp. 719-727, 1999.

[31] R. B. Berry et al., "Rules for scoring respiratory events in sleep: update of the 2007 AASM manual for the scoring of sleep and associated events. Deliberations of the sleep apnea definitions task force of the American Academy of Sleep Medicine," Journal of Clinical Sleep Medicine, vol. 8, no. 5, pp. 597-619, 2012.

[32] W. S. Bahnasy, Y. A. E. El-Heneedy, E. A. S. El-Seidy, N. A. A. Labib, and I. S. E. Ibrahim, "Sleep disturbances in diabetic peripheral neuropathy patients: a clinical and polysomnographic study," The Egyptian Journal of Neurology, Psychiatry and Neurosurgery, vol. 54, no. 1, p. 23, 2018.

[33] N. Siwasaranond, H. Nimitphong, A. Manodpitipong et al., "The relationship between diabetes-related complications and obstructive sleep apnea in type 2 diabetes," Journal Diabetes Research, vol. 2018, article 9269170, 9 pages, 2018.

[34] E. R. Winkelmann, G. R. Chiappa, C. O. C. Lima, P. R. N. Viecili, R. Stein, and J. P. Ribeiro, "Addition of inspiratory muscle training to aerobic training improves cardiorespiratory responses to exercise in patients with heart failure and inspiratory muscle weakness," American Heart Journal, vol. 158, no. 5, pp. 768.e1-768.e7, 2009.

[35] I. M. B. S. Pessoa, M. H. Neto, D. Montemezzo, L. A. M. Silva, A. D. De Andrade, and V. F. Parreira, "Predictive equations for respiratory muscle strength according to international and Brazilian guidelines," Brazilian Journal of Physical Therapy, vol. 18, no. 5, pp. 410-418, 2014.

[36] J. W. Evans and W. A. Whitelaw, "The assessment of maximal respiratory mouth pressures in adults," Respiratory Care, vol. 54, no. 10, pp. 1348-1359, 2009.

[37] C. A. de Castro Pereira, A. A. O. Duarte, A. Gimenez, and M. R. Soares, "Comparison between reference values for FVC, FEV1, and FEV1/FVC ratio in White adults in Brazil and those suggested by the Global Lung Function Initiative 2012," Jornal Brasileiro de Pneumologia, vol. 40, no. 4, pp. 397-402, 2014.

[38] A. K. F. Souza, A. Dornelas de Andrade, A. I. C. de Medeiros et al., "Effectiveness of inspiratory muscle training on sleep and functional capacity to exercise in obstructive sleep apnea: a randomized controlled trial," Sleep \& Breathing, vol. 22, no. 3, pp. 631-639, 2018.

[39] F. Kılıçlı, S. Dökmetaş, F. Candan et al., "Inspiratory muscle strength is correlated with carnitine levels in type 2 diabetes," Endocrine Research, vol. 35, no. 2, pp. 51-58, 2010.

[40] T. Meyer, T. Georg, C. Becker, and W. Kindermann, "Reliability of gas exchange Measurements from two different spiroergometry systems," International Journal of Sports Medicine, vol. 22, no. 8, pp. 593-597, 2001.
[41] R. N. Aurora and N. M. Punjabi, "Obstructive sleep apnoea and type 2 diabetes mellitus: a bidirectional association," The Lancet Respiratory Medicine, vol. 1, no. 4, pp. 329-338, 2013.

[42] T. Rehling, A. M. Banghøj, M. H. Kristiansen, L. Tarnow, and S. Molsted, "Reduced inspiratory muscle strength in patients with type 2 diabetes mellitus and obstructive sleep apnoea," Journal Diabetes Research, vol. 2017, article 4121794, 6 pages, 2017.

[43] K. L. Shepherd, C. M. Jensen, K. J. Maddison, D. R. Hillman, and P. R. Eastwood, "Relationship between upper airway and inspiratory pump muscle force in obstructive sleep apnea," Chest, vol. 130, no. 6, pp. 1757-1764, 2006.

[44] P. E. Peppard, T. Young, M. Palta, and J. Skatrud, "Prospective study of the association between sleep-disordered breathing and hypertension," The New England Journal of Medicine, vol. 342, no. 19, pp. 1378-1384, 2000.

[45] F. J. Nieto, T. B. Young, B. K. Lind et al., “Association of sleepdisordered breathing, sleep apnea, and hypertension in a large community-based study: Sleep Heart Health Study," JAMA, vol. 283, no. 14, pp. 1829-1836, 2000.

[46] S. D. Herkenrath, M. Treml, C. Priegnitz, W. Galetke, and W. J. Randerath, "Effects of respiratory muscle training (RMT) in patients with mild to moderate obstructive sleep apnea (OSA)," Sleep \& Breathing, vol. 22, no. 2, pp. 323-328, 2018.

[47] D. M. Mancini, D. Henson, J. L. Manca, L. Donchez, and S. Levine, "Benefit of selective respiratory muscle training on exercise capacity in patients with chronic congestive heart failure," Circulation, vol. 91, no. 2, pp. 320-329, 1995.

[48] I. Laoutaris, A. Dritsas, M. D. Brown, A. Manginas, P. A. Alivizatos, and D. V. Cokkinos, "Inspiratory muscle training using an incremental endurance test alleviates dyspnea and improves functional status in patients with chronic heart failure," European Journal of Cardiovascular Prevention and Rehabilitation, vol. 11, no. 6, pp. 489-496, 2004.

[49] G. R. Chiappa, B. T. Roseguini, P. J. C. Vieira et al., "Inspiratory muscle training improves blood flow to resting and exercising limbs in patients with chronic heart failure," Journal of the American College of Cardiology, vol. 51, no. 17, pp. 16631671, 2008.

[50] J. P. Ribeiro, G. R. Chiappa, and C. C. Callegaro, "The contribution of inspiratory muscles function to exercise limitation in heart failure: pathophysiological mechanisms," Revista Brasileira de Fisioterapia, vol. 16, no. 4, pp. 261-267, 2012.

[51] N. Hart, K. Sylvester, S. Ward, D. Cramer, J. Moxham, and M. I. Polkey, "Evaluation of an inspiratory muscle trainer in healthy humans," Respiratory Medicine, vol. 95, no. 6, pp. 526-531, 2001.

[52] M. Sasaki, H. Kurosawa, and M. Kohzuki, "Effects of inspiratory and expiratory muscle training in normal subjects," Journal of the Japanese Physical Therapy Association, vol. 8, no. 1, pp. 29-37, 2005.

[53] S. Adamopoulos, J. P. Schmid, P. Dendale et al., "Combined aerobic/inspiratory muscle training vs. aerobic training in patients with chronic heart failure: the Vent-HeFT trial: a European prospective multicentre randomized trial," European Journal of Heart Failure, vol. 16, no. 5, pp. 574-582, 2014.

[54] D. E. Mills, M. A. Johnson, Y. A. Barnett, W. H. T. Smith, and G. R. Sharpe, "The effects of inspiratory muscle training in older adults," Medicine and Science in Sports and Exercise, vol. 47, no. 4, pp. 691-697, 2015. 
[55] K. Hill, N. M. Cecins, P. R. Eastwood, and S. C. Jenkins, "Inspiratory muscle training for patients with chronic obstructive pulmonary disease: a practical guide for clinicians," Archives of Physical Medicine and Rehabilitation, vol. 91, no. 9, pp. 1466-1470, 2010.

[56] T. P. Olson, M. J. Joyner, N. M. Dietz, J. H. Eisenach, T. B. Curry, and B. D. Johnson, "Effects of respiratory muscle work on blood flow distribution during exercise in heart failure," The Journal of Physiology, vol. 588, no. 13, pp. 2487-2501, 2010 . 